\title{
Equipment Sizing and Method for the Application of Exhaust Gas Waste Heat to Food Crops Drying Using a Hot Air Tray Dryer
}

\section{Ononogbo ${ }^{1, *}$, O.C. Nwufo ${ }^{2}$, C.A. Okoronkwo², N.V. Ogueke ${ }^{2}$, J.O. Igbokwe ${ }^{2}$ and E.E. Anyanwu ${ }^{2}$}

\author{
1Department of Mechanical Engineering Technology, Imo State Polytechnic, \\ Umuagwo, Owerri, Imo State, Nigeria \\ 2Department of Mechanical Engineering, Federal University of Technology, Imo State, \\ Nigeria
}

Article Type: Article

Article Citation: Ononogbo C, Nwufo OC, Okoronkwo CA, Ogueke NV, Igbokwe J0, Anyanwu EE. Equipment sizing and method for the application of exhaust gas waste heat to food crops drying using a hot air tray dryer. Indian Journal of Science and Technology. 2020; 13(05),502-518.D0l:10.17485/ijst/2020/ v013i05/145593

Received date: June 29, 2019

Accepted date: 0 ctober 18, 2019

*Author for correspondence: $C$. Ononogbo petermaryco@yahoo. com 9 Department of Mechanical Engineering Technology, Imo State Polytechnic, Umuagwo, Owerri, Imo State, Nigeria

\begin{abstract}
Objectives: Equipment sizing and method of utilizing exhaust gas waste heat for food crops drying are presented. Methods/findings: The sizing of the components of the equipment was achieved using known design principles. The system uses an axial flow turbine and a heat exchanger to harness the energy of the exhaust gas of a diesel engine generator. A $250 \mathrm{kVA}$ generator with measured exhaust gas flow rate and temperature of $44.5 \mathrm{~m}^{3} / \mathrm{min}$ and $382.7^{\circ} \mathrm{C}$ was selected for this work. The purpose of the recovered energy is for the drying of food crops. An arduino platform was used to control the operation of the components of the dryer. The drying chamber consists of three trays whose calculated total volume per batch is $0.0463 \mathrm{~m}^{3}$. Weight losses across the trays, drying air temperature and humidity in the chamber are monitored by sensors. The test rig of the sized and fabricated equipment is currently undergoing extensive experimentation. Preliminary investigation of the dryer showed that the drying air in the chamber initially at the temperature and humidity of $31{ }^{\circ} \mathrm{C}$ and $71.2 \%$ was heated to $88^{\circ} \mathrm{C}$ and $22.3 \%$ when the dryer operated without load for $45 \mathrm{~min}$ at an air speed of $2.0 \mathrm{~m} / \mathrm{s}$. Application: After cooling and maintaining the drying chamber averagely at $59^{\circ} \mathrm{C}$, each tray was loaded with $400 \mathrm{~g}$ of the grains of freshly harvested maize. The dryer was allowed to run for $30 \mathrm{~min}$ and the results obtained showed weight losses of $127.81 \mathrm{~g}, 118.36$ $\mathrm{g}$, and $116.91 \mathrm{~g}$ for the grains in trays 1,2, and 3, respectively. The application of this energy recovery system to the drying of food products, would help to save a considerable amount of primary fuel which is considered a viable means of cost saving and amelioration of environmental degradation.
\end{abstract}

Keywords: Waste Heat Recovery, Drying, Global Warming, Environment, Cost Saving, Food Quality. 


\section{Introduction}

There is high demand for fuel as a result of expansion in population, urbanization, and industrialization, which has resulted to increase in fuel costs. For this reason, efforts are being made to make energy use more efficient. Obviously, higher energy conversion or its utilization translates to reduced cost of energy globally. One technique of ensuring high energy efficiency is the use of waste heat recovery systems. Recently, huge efforts are directed to the reduction of the amount of energy that is wasted into the environment. And the ultimate aim is to help in the conservation of exhaustible reserves of fossil fuels, reduction of the carbon footprint and the battling of global climate change as well as the improvement of process economics. According to Ref. [1], waste heat is heat that is produced in a process as a result of fuel combustion or chemical reaction, and then discarded into the environment even though it could still be harnessed for a purpose that is useful and economic. Diminishing petroleum supplies and increasing fuel costs are causing governments and industries to look for ways to increase the power efficiency of engines [2]. An internal combustion (IC) engine heat balance shows that the input energy is approximately split into three equal portions such as the energy put to useful work, energy lost to coolant, and energy lost to the environment with the exhaust gases. Hopefully, with the emerging discoveries on exhaust heat recovery to increase the efficiency of IC engines, world energy demand for the depleting fossil fuel reserves would be reduced and hence the impact of global warming [3-4]. It is widely believed that almost $70 \%$ of the energy released from the fuel by an engine is lost, mostly in the form of heat. In Ref. [5], Pradip and Hole reported that approximately $25-30 \%$ of the energy generated by engines is dissipated in the form of energy loss through the exhaust gas. In Ref. [6-7], authors stated that the waste heat produced from the thermal combustion process in IC engines which is lost to the environment through an exhaust pipe could get as high as 30-40\%. Basically, the direct dumping of exhaust gases into the surroundings, not only wastes energy but also contributes to the damage of the environment. However, several innovative cooling and exhaust heat recovery systems have been introduced to reduce cooling loss and regenerate the power by recovering the waste heat [4]. In recent times, large efforts have been committed towards the recovery of waste thermal energy in vehicles and other waste heat generating industrial machines. Interestingly, it could be surmised from the foregoing that the energy released through the exhaust of IC engines is of the same magnitude as the mechanical power generated by the engine.

Waste heat losses from combustion processes in IC engines are inevitable. Therefore, some facilities can be used to reduce these losses by either improving the equipment efficiency or by the installation of waste heat recovery technologies. The recovered energy could be used in preheating combustion air, space heating, electricity generation, etc. Three essential components are required for waste heat recovery, namely: (i) a source of waste heat that is accessible, (ii) a technique for its recovery, and (iii) an application for the recovered heat. The method required for the heat recovery partly depends on the temperature of the available waste heat and the economics involved. Generally, the higher the temperature of waste heat, the higher the value which makes the heat recovery more cost effective. The temperatures of exhaust gases immediately leaving the engine are as 
high as $450-600{ }^{\circ} \mathrm{C}$ [2]. Table 1 shows a survey of exhaust gas temperatures from various internal combustion engines of automotive vehicles and stationary engines.

Although technologies of energy recovery are available, there are still large potentials for their application, which according to Ref. [8] have not yet been realized in industries. There are numerous technologies used for waste heat recovery such as heat exchangers, thermoelectric devices, turbo compounds, etc. In this work, the source of waste heat energy to be accessed is the high temperature exhaust gas from a $250 \mathrm{kvA}$ diesel generator. It involves recovery or conversion of energy of the exhaust gas to useful work. Captured and reused waste heat is an emission-free substitute for costly purchased fuels or electricity. By this recovery system, the impact of the pollutants to the environment is significantly reduced. The recovery technology to be employed is an axial flow turbine and a heat exchanger while the energy recovered is to be used for drying agricultural products. Large amounts of agricultural products perish yearly during post-harvest periods because of their relatively high moisture content. Basically, Nigeria is blessed with a landmass of 98.3 million hectares of which $72 \%$ is considered suitable for agricultural production [9]. Statistics show that the rate of growth in the area of food production is very low, amounting to $2.5 \%$ per annum [10]. According to Ref. [11], the poor growth is attributable to the poor level of food preservation in the country. However, efforts are being made with a view to achieving improvement in food production in a given number of ways such as drying of agricultural products. This encourages farmers to embark on large scale agricultural activities as long as ways of preserving their harvested crops are available. Many agricultural products require long drying times ranging from $5 \mathrm{~min}$ to $73 \mathrm{~h}$ with optimum drying air temperatures requiring large quantity of energy that results in high overhead drying cost and high prices of dried food products [12-13]. For most food products, it is best to use drying temperatures of $50{ }^{\circ} \mathrm{C}$ to $55^{\circ} \mathrm{C}$; and the temperature should never exceed $60{ }^{\circ} \mathrm{C}$ [14]. This is because higher temperatures destroy nutrients contained in the food which causes the food to lose its dietary value. When higher temperatures are used, food cooks instead of drying, which results in case hardening where the food dries on outside but moisture trapped inside allowing mold growth [14].

There are many types of dryers operated by different energy sources like solar energy, bioenergy, electrical energy, etc. Most of the energy sources involved in these operations have some associated setbacks in terms of their availability and costs. This makes the end products more expensive. Although sun drying is the cheapest and oldest method of food

TABLE 1. Temperature range for diesel engines

\begin{tabular}{llc}
\hline S/N & Engine & Temperature $\left({ }^{\circ} \mathbf{C}\right)$ \\
\hline 1 & Single cylinder four stroke diesel engine & 456 \\
2 & Four cylinder four stroke diesel engine (Tata Indica) & 448 \\
3 & Six cylinder four stroke diesel engine (Tata Truck) & 336 \\
4 & Four cylinder four stroke diesel engine (Mahindra Arjun 605 & 310 \\
& DI) & 383 \\
5 & Genset (Kirloskar) at power 198hp & 396 \\
6 & Genset (Cummims) at power 200hp & \\
\hline
\end{tabular}

Source: In Ref. [12]. 
preservation but it exposes the crop to contamination by dust, insect attack and infection by microbes and yet it is not always available. There are different drying methods that are available to ensure continuous high quality food supply. In this work, a hot air tray dryer using exhust gas waste heat as energy source is considered for the drying of food crops. Tray dryers are widely used in agricultural drying due to their capability to dry products irrespective of time and weather conditions [15]. Among all the drying techniques, the tray dryer is the most extensively used because of its simple and economic design [15]. The food is spread out on trays at an acceptable thickness so that the product can be dried uniformly. Heating may be produced by hot air stream across the trays, conduction from heated trays, or radiation from heated surfaces. In a tray dryer, more products can be loaded as the trays are arranged at different levels. Tray dryers have the capability of drying products at high volume. The key to its successful operation is the uniform airflow distribution over the trays [16].

\section{Materials and Methods}

\subsection{Configuration of the Waste Energy Recovery System}

The configuration for the exhaust gas waste energy recovery system from a turbocharged $250 \mathrm{kVA}$ Perkins diesel generator is shown in Figure 1. Here, part of the energy of the exhaust gas is recovered by a turbine and used to drive an electrical generator (dynamo) which in turn is used to charge a battery of $12 \mathrm{~V} 7.5 \mathrm{Ah}$. This battery produces the electric power needed to drive the air blower and other devices. The exhaust gas leaving the housing

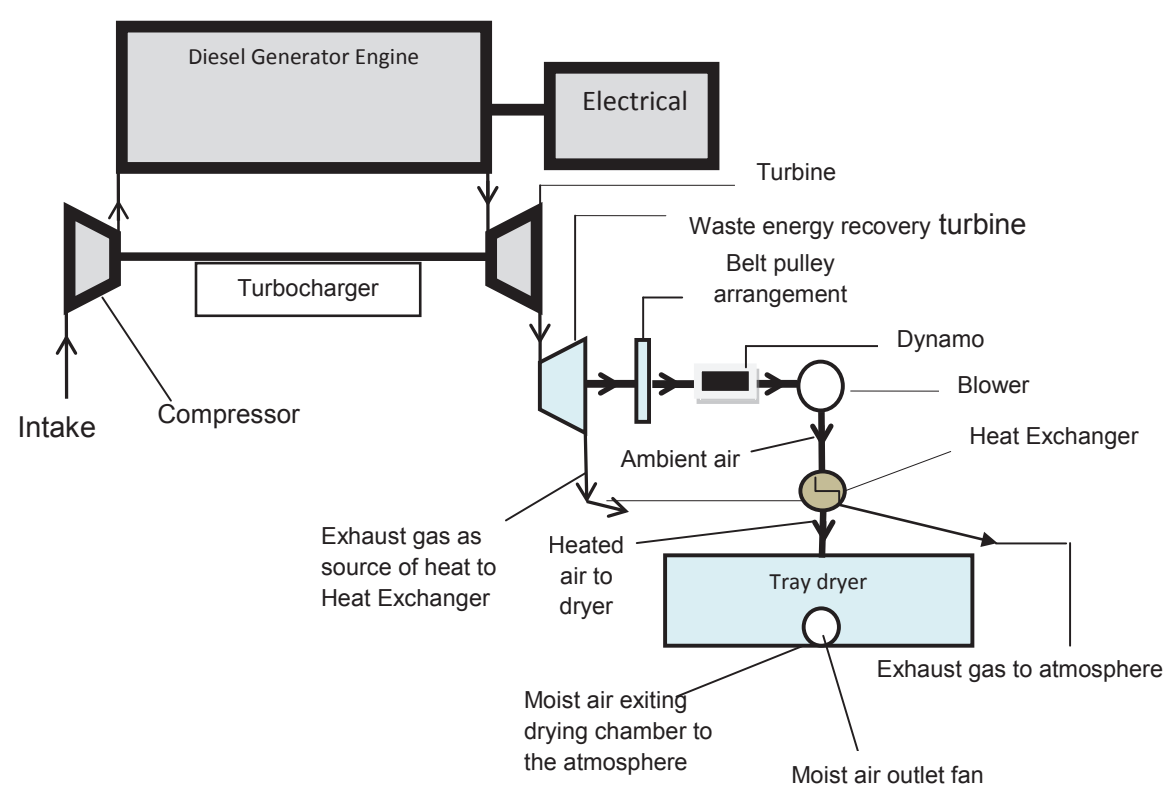

FIGURE 1. The system configuration of the turbine-dryer arrangement for waste energy recovery. 
of the energy recovery turbine enters the heat exchanger to raise the temperature of the ambient air (drying air) drawn into the heat exchanger by the air blower. The heated air is then routed to the drying chamber of the tray dryer for the purpose of drying food crops.

The turbine rotor is directly attached to the main shaft connected to the smaller pulley (driving-pulley) as seen in the isometric view of the heat recovery system, Figure 2, while the driven pulley of a larger diameter has a common shaft with the dynamo which generates the electrical energy required in the system. The axial turbine unit, apart from some load bearings, has as its main part as a row of aerodynamically shaped objects (stator) which do not move and a row of aerodynamically shaped objects (rotor) which move and provide the torque to the shaft, and the entire components are placed in a housing as seen in Figure 2. The whole unit is connected to the exhaust gas tail pipe outlet of the generator causing the rotor blades to spin in the exhaust gas streams.

During operation, the exhaust gas travels in the axial direction and enters through the inlet cone, where the fluid slows down to the selected inlet conditions of the blades of the stator. Then the stator blades set the speed and angle at which the exhaust gas must enter the rotor. When the exhaust gas stream strikes the turbine rotor blades by virtue of its kinetic energy, the rotor blades spin providing torque to the shaft which rotates the driving-pulley. The exhaust gas which is still at high temperature exits the turbine housing and enters the heat exchanger where it heats up the ambient air drawn in by the blower (inlet fan). The heated air is then routed through the drying chamber of a tray dryer in

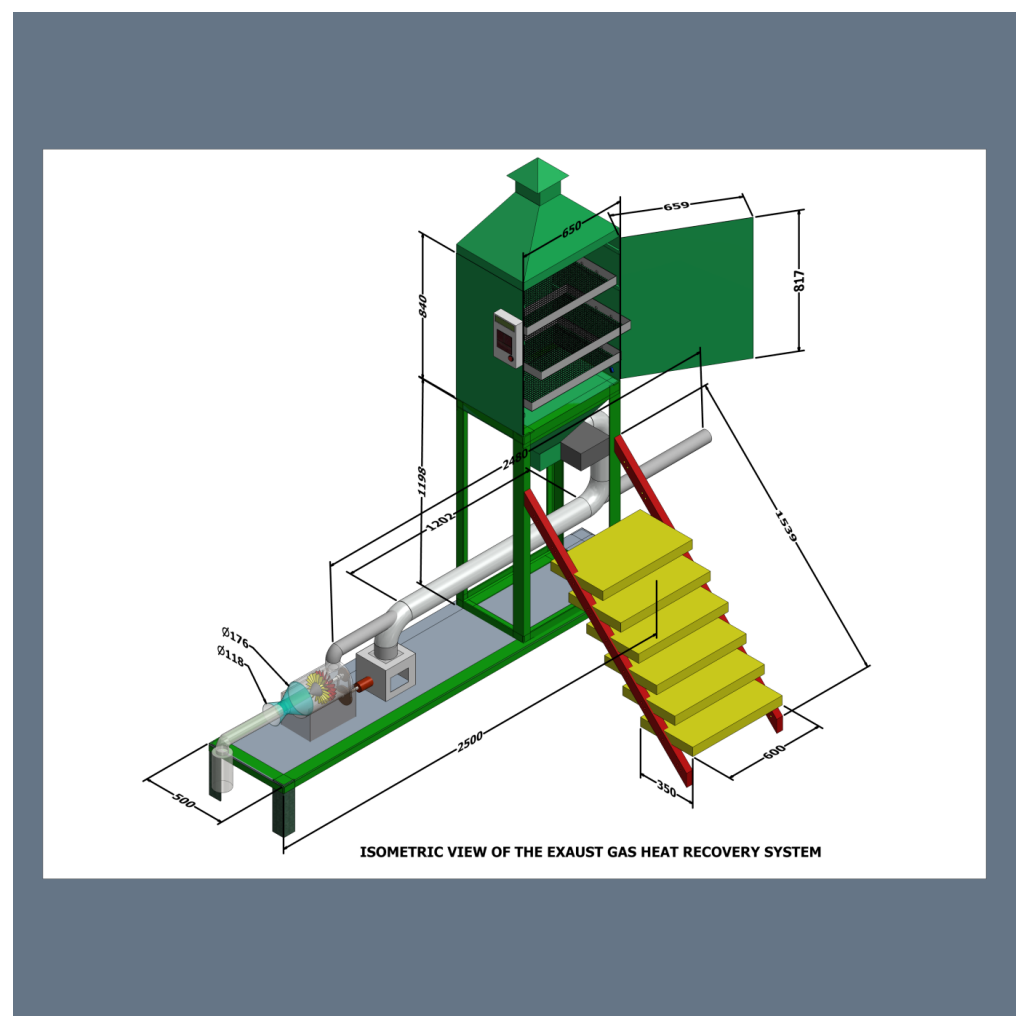

FIGURE 2. Isometric view of the exhaust gas heat recovery system. 
order to dry the product loaded in the trays. The exploded view of the heat recovery system is shown in Figure 3.

\subsection{Selection of the Axial Flow Turbine}

The values of the baseline parameters such as the Exhaust gas flow rate, $\dot{V}$ and Inlet temperature of the exhaust gas to the stator, $T_{01}$ are $44.5 \mathrm{~m}^{3} / \mathrm{min}$ and $655.7 \mathrm{~K}$, respectively. In addition to this, the following preliminary assumptions as seen in Table 2 are used for the selection of the axial flow heat recovery turbine.

Where $c_{2}$ is the absolute velocity at inlet of the rotor; $V_{3}$ is the relative velocity at exit of the rotor; $c_{3}$ is the absolute velocity at exit of the rotor, and $V_{2}$ is the relative velocity at inlet of the rotor. Based on the mass flow rate of the fluid and the area upon which it enters the turbine, the initial absolute velocity can be calculated with the flow entering an axial turbine being in an axial direction [17]. The expressions for the annulus areas of the turbine at the various stations, $A_{i}$, the mass flow rate, $\dot{\mathrm{m}}$ of the exhaust gas, the blade loading coefficient, $\varphi$, the blade heights, $b_{i}$ and the degree of reaction, $R_{d}$ are given below:

$$
A_{i}=\frac{\dot{m}}{\rho_{i} c_{a i}}
$$

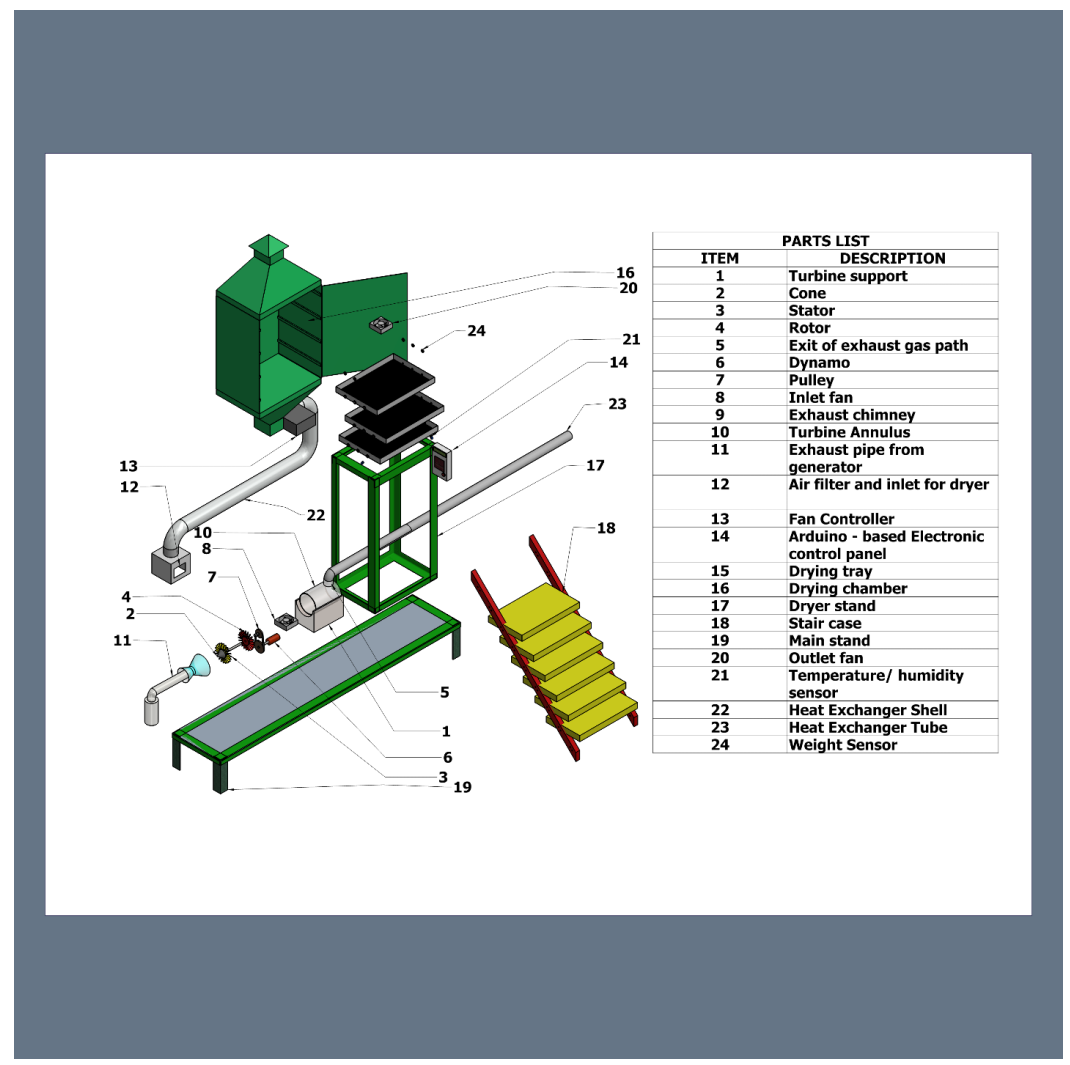

FIGURE 3. Exploded view of the exhaust gas heat recovery system. 
TABLE 2. Assumptions for preliminary selection

\begin{tabular}{ll}
\hline Parameter & Value \\
\hline 1. Temperature drop, $\Delta \boldsymbol{T}_{0}(\mathrm{~K})$ & 3 \\
2. Mean blade speed, $U_{m}(\mathrm{~m} / \mathrm{s})$ & 43 \\
3. Nozzle loss coefficient, $\boldsymbol{i}_{\boldsymbol{N}}$ & 0.052 \\
4. Flow coefficient, $\varnothing$ & 0.80 \\
5. Inlet pressure $(\mathrm{kPa})$ & 1.8 \\
6. Pressure ratio, $\frac{\boldsymbol{P}_{01}}{\boldsymbol{P}_{03}}$ & 1.52 \\
7. Rotational speed of shaft, $N_{b}(\mathrm{rpm})$ & 5,100 \\
8. $\boldsymbol{c}_{2}=\boldsymbol{V}_{3} ; \boldsymbol{c}_{3}=\boldsymbol{V}_{2}$ & \\
\hline
\end{tabular}

$$
\begin{gathered}
\dot{m}=V \times \rho_{2} \\
\varphi=\frac{2 c_{p} \Delta T_{0 s}}{U_{m}^{2}} \\
b_{i}=\frac{A_{i} N_{b}}{U_{m}} \\
R_{d}=\frac{h_{2}-h_{3}}{h_{1}-h_{3}}=\frac{T_{2}-T_{3}}{T_{1}-T_{3}}
\end{gathered}
$$

Where the subscript $i$ represents the different stations of the turbine stage, 1, 2, and 3 . However, $h_{1}, h_{2}$, and $h_{3}$ are the enthalpies of the exhaust gas at inlet to the stator, at entry to the rotor, and at exit from the rotor, respectively. Similarly, $T_{1}, T_{2}$, and $T_{3}$ are the static temperatures at the stated positions. $\rho_{2}$ is the density of the exhaust gas at inlet of the rotor. The gas angles of the velocity triangles are calculated at the mean radius using the following equations:

$$
\begin{gathered}
\tan \beta_{3}=\frac{1}{2 \varnothing}\left(\frac{\varphi}{2}+2 R_{d}\right) \\
\tan \beta_{2}=\frac{1}{2 \varnothing}\left(\frac{\varphi}{2}-2 R_{d}\right) \\
\tan \alpha_{3}=\tan \beta_{3}-\frac{1}{\varnothing} \\
\tan \alpha_{2}=\tan \beta_{2}+\frac{1}{\varnothing}
\end{gathered}
$$


where $\alpha$ is the angle made by the absolute velocity with the axial direction, $\beta$ is the angle the relative velocity makes with the axial direction. Figure 4 shows the superimposed diagram of the velocity triangles. $\Delta c_{w}$, as seen in Figure 4 is the change in the velocity of whirl while $c_{w 2}$ and $c_{w 3}$ are whirl velocities.

\subsection{Flow Parameters at the Outlet of the Stator}

Considering the geometry of the superimposed velocity diagram above, the following equations can be derived:

$$
\begin{aligned}
& c_{a i}=U_{m} \varnothing \\
& c_{i}=\frac{c_{a i}}{\cos \alpha_{i}}
\end{aligned}
$$

The temperature equivalent of the exit velocity is:

$$
T_{02}-T_{2}=\frac{c_{2}^{2}}{2 c_{p}}
$$

For a single stage turbine, it is assumed that $\alpha_{1}=0$ since $c_{1}$ is axial; and this together with the assumptions that $c_{1}=c_{3}$ and $c_{a 3}=c_{a 2}$, yields,

$$
c_{a 1}=c_{1}=c_{3}
$$

For choke conditions at the outlet of the stator, we have that,

$$
T_{2}-T_{2}^{I}=\mu_{N}\left(\frac{c_{2}^{2}}{2 c_{p}}\right)
$$

$P_{2}$ is calculated from the reversible adiabatic relation:

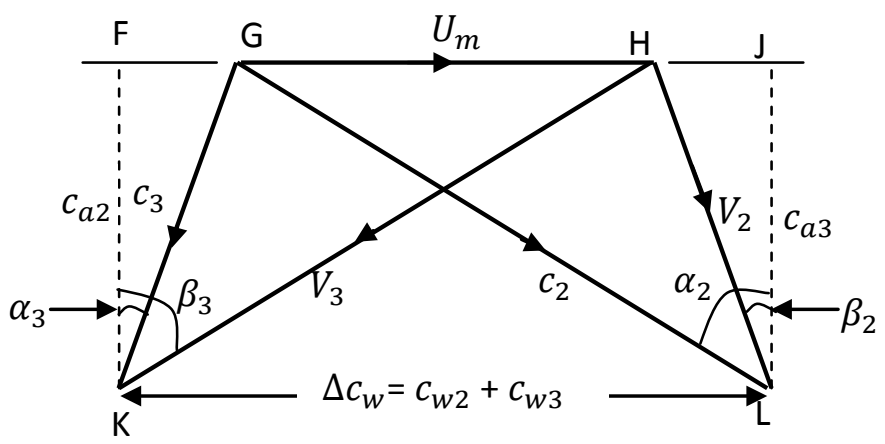

FIGURE 4. Schematic of the superimposed velocity diagram of the single stage reaction turbine. 


$$
\frac{P_{01}}{P_{2}}=\left(\frac{T_{01}}{T_{2}^{I}}\right)^{\frac{\gamma}{\gamma-1}}
$$

Neglecting the frictional effect on the critical pressure ratio, we have that:

$$
\frac{P_{01}}{P_{c}}=\left(\frac{\gamma+1}{2}\right)^{\frac{\gamma}{\gamma-1}}
$$

Calculation of the densities at various stations of the turbine stage is obtained using equation (17):

$$
\rho_{i}=\frac{P_{i}}{R T_{i}}
$$

The temperatures equivalent of the entry and exit kinetic energies are:

$$
T_{01}-T_{1}=\frac{c_{1}^{2}}{2 c_{p}}
$$

and

$$
T_{3}=T_{03}-\frac{c_{3}^{2}}{2 c_{p}}
$$

The reversible adiabatic relation at station 3 is given by:

$$
P_{3}=P_{03}\left(\frac{T_{3}}{T_{03}}\right)^{\frac{\gamma}{\gamma-1}}
$$

The radius ratio of the annulus can be found from equation (20),

$$
\frac{r_{t}}{r_{m}}=\frac{r_{m}+\frac{b}{2}}{r_{m}-\frac{b}{2}}
$$

and

$$
r_{m}=\frac{r_{t}+r_{r}}{2}
$$

where $r_{r}$ is the root radius of the turbine, $r_{m}$ is the mean radius, and $r_{t}$ is the tip radius, respectively. From [18], the power output of the turbine, $P_{\text {out }}$ is given by:

$$
P_{\text {out }}=\dot{m} U_{m} \Delta C_{w}
$$

where $\Delta C_{w}$ is the change in the velocity of whirl as seen in Figure 4. 
The calculated dimensions of the annulus as well as the values of the parameters at various stations of the turbine are presented in Table 3:

TABLE 3. Annulus dimensions and parameters of the turbine at various stations

\begin{tabular}{lccccccccccc}
\hline Station & $A\left(\mathrm{~m}^{2}\right)$ & $\mathbf{b}(\mathrm{m})$ & $\boldsymbol{r}_{\boldsymbol{t}} / \boldsymbol{r}_{\boldsymbol{m}}$ & $\boldsymbol{p}\left(\boldsymbol{k g} / \boldsymbol{m}^{3}\right)$ & $\boldsymbol{c}_{\boldsymbol{a}}(\boldsymbol{m} / \boldsymbol{s})$ & $\boldsymbol{c}(\boldsymbol{m} / \boldsymbol{s})$ & $\boldsymbol{P}^{\cdot(\mathrm{bar})}$ & $\mathrm{T}(\mathrm{K})$ & $\boldsymbol{\alpha}\left({ }^{\circ}\right)$ & $\boldsymbol{\beta}\left({ }^{\circ}\right)$ \\
\hline 1 & 0.0188 & 0.03724 & 1.602 & 0.9540 & 39.081 & 39.081 & 1.793 & 655.04 & 0 & 0 \\
2 & 0.0216 & 0.0427 & 1.722 & 0.9464 & 34.400 & 70.510 & 1.775 & 653.53 & 28.33 & 60.8 \\
3 & 0.0324 & 0.0641 & 2.323 & 0.6302 & 34.400 & 39.081 & 1.179 & 652.04 & 60.8 & 28.33 \\
\hline
\end{tabular}

\subsection{Description and Sizing of the Hot Air Tray Dryer and the Heat Exchanger}

The tray dryer consists of seven major components, namely: the drying chamber, the trays, the chimney, the heat source, the temperature and humidity sensors, the strain gauge weight sensors, and the moist air outlet fan.

The dryer operates on the principle of batch drying. The dryer consists of a drying chamber where the products to be dried are fed before drying commences. Heat is supplied to the chamber by the air which is heated up by the exhaust gas passing through the heat exchanger. The heat energy supplied to the dryer is part of the heat recovered from the exhaust gas energy of the diesel generator. The blower powered by the electrical energy from the dynamo is connected to the heat exchanger into which it draws in ambient air to be heated up by the exhaust gas passing through the heat exchanger. The air heated by the heat exchanger expands and travels upwards into the drying chamber. The food crops to be dried are spread on wire gauze trays inside the drying chamber. As the warm air moves and circulates across the surface of the food crops, it picks up moisture. The air that has picked up moisture on its way through the drying chamber leaves the chamber through the chimney provided at the top of the dryer. The effectiveness of the evacuation of moist air through the chimney is enhanced by the use of a moist air outlet fan placed near the top of the dryer. The cooled exhaust gas passing through the heat exchanger is then released into the atmosphere through a pipe whose outlet is at a reasonable height and distance away from the dryer to avoid the contamination of the surrounding air to be used for drying. However, black carbon (a fine particle of $\mathrm{PM}_{2.5}$ emitted from diesel engines) and other larger airborne particles which settle faster due to gravity [19] may pose a danger of contamination to the drying air. Therefore, the drying air to be heated is drawn into the heat exchanger by the aid of a blower whose box is covered with a mesh air filter of $2 \mu \mathrm{m}$ size in order to prevent these particles from being sucked into the drying chamber. To preserve the quality of the food crops during drying, the temperature of the drying chamber is controlled so that it does not exceed $60^{\circ} \mathrm{C}$. The temperature of the drying chamber is monitored using sensors. However, above this temperature, the temperature sensors give a signal to the control system which cuts off the flow of heated air into the chamber by switching off the air 
blower until the chamber temperature falls to $50{ }^{\circ} \mathrm{C}$ (which as stated above is within the range of acceptable drying temperatures) before the operation of the blower is activated once again. The whole control processes in terms of temperature and velocity regulation of the drying air within the drying chamber are made possible by the use of an arduino platform. The 3-D view of the dryer is shown in Figure 2, while the schematic diagram of the dryer is shown in Figure 5. The dryer has been fabricated using the following materials: (i) Equal length angle steel for constructing the dryer frame; (ii) Mild steel sheet for covering the external part of the drying chamber; and (iii) Fiber glass used as a lagging material for the thermal insulation of the dryer. The trays of the dryer were constructed using galvanized steel wire gauze with aluminum profile base. The aim of using galvanized steel wire gauze is to avoid the problem of rust of the tray material and contamination of products to be dried.

\subsection{The Dimensions of the Trays and the Drying Chamber}

The drying chamber is composed of three (3) trays with the total volume, of products to be dried per batch equal to $0.04628 \mathrm{~m}^{3}$. The length, $l_{t}$, width, $w_{t}$ and height, $H_{t}$ of the trays are $0.66 \mathrm{~m}, 0.468 \mathrm{~m}$, and $0.05 \mathrm{~m}$, respectively. The head and bottom spaces of the dryer from the trays, $\mathrm{H}_{\mathrm{hs}}$ and $\mathrm{H}_{\mathrm{bs}}$ are $0.12 \mathrm{~m}$ and $0.17 \mathrm{~m}$ while the tray thickness, $T_{t}$ and the space between the trays, $S_{t}$ are $0.005 \mathrm{~m}$ and $0.09 \mathrm{~m}$, respectively. The drying chamber height, $H_{C}, 0.71 \mathrm{~m}$ is obtained using the expression:

$$
H_{c}=3 \times H_{t}+3 \times T_{t}+2 \times S_{t}+H_{h s}+H_{b s}
$$

\subsection{Water Removal from Products to be Dried and Heat Requirement for Drying}

Weight loss from wet to dried product is calculated from Ref. [20], where the mass of dry product is given by:

$$
M_{d}=\frac{m_{w}\left(100-\varnothing_{o}\right)}{100-\varnothing_{f}}
$$

where $m_{w}$ is the total mass of wet product per batch, $\varnothing_{o}$ is the percentage maximum moisture content of freshly harvested product, and $\varnothing_{f}$ is final moisture content after drying. Thus, the mass of water to be removed, $M_{w}$ is

$$
M_{w}=m_{w}-M_{d}
$$

According to Ref. [20], the quantity of heat required to remove water from the product is given by: 


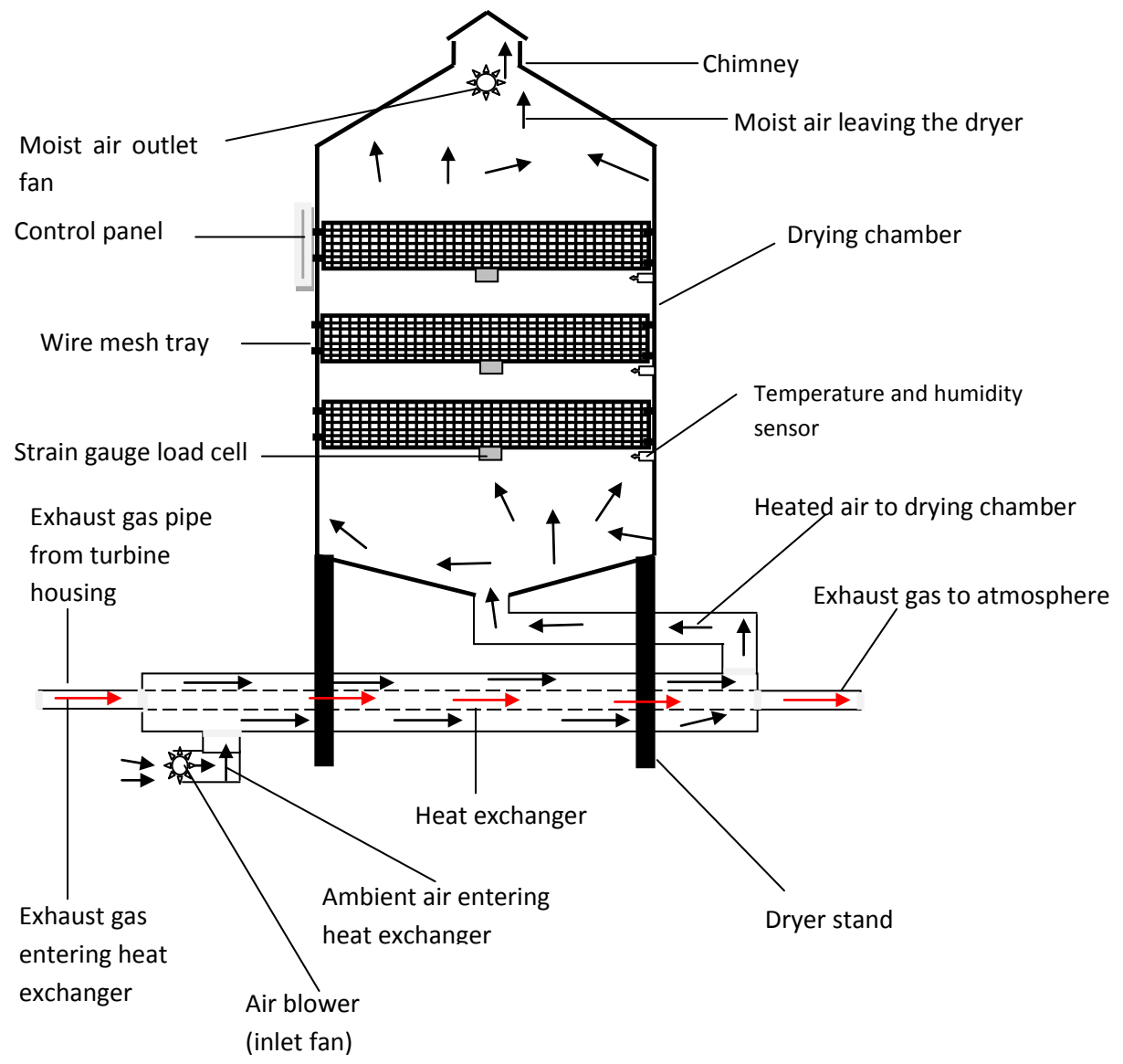

FIGURE 5. Schematic diagram of the hot air tray dryer.

$$
Q=m_{w} \times c_{c}\left(T_{d p}-T_{i c}\right)+M_{w} L
$$

where $L$ is the latent heat of vaporization of water $(2256 \mathrm{~kJ} / \mathrm{kg}), T_{d p}$ is the temperature of the drying product, and $T_{i c}$ is the initial temperature of the drying chamber. The rate of heat transfer, $\dot{Q}$ between the exhaust gas and the ambient air in the heat exchanger is given by Ref. [21] to be:

$$
\dot{Q}=\frac{Q}{\text { time }(\mathrm{s})}
$$

The temperature of the exhaust gas at the exit of the heat exchanger, $t_{g 2}$ can be obtained from the heat transfer rate $(\dot{Q})$ expression:

$$
\dot{Q}=\dot{m}_{g} c_{p g}\left(t_{g 1}-t_{g 2}\right)
$$

where $c_{p g}$ is specific heat of exhaust gas at constant pressure, $\dot{m}_{g}$ is mass flow rate of exhaust gas, and $t_{g 1}$ is the temperature of the exhaust gas at the inlet of the heat exchanger. 
The logarithmic mean temperature difference (LMTD), $\theta_{m}$ is used to determine the area and length of the heat exchanger to be used, and is given by Ref. [22], as:

$$
\theta_{m}=\frac{\theta_{1}-\theta_{2}}{\operatorname{In}\left(\frac{\theta_{1}}{\theta_{2}}\right)}=\frac{\left(t_{g 1}-t_{a 1}\right)-\left(t_{g 2}-t_{a 2}\right)}{\operatorname{In}\left[\left(t_{g 1}-t_{a 1}\right) /\left(t_{g_{2}}-t_{a 2}\right)\right]}
$$

While the overall heat transfer coefficient, $U$ according to [22] is given by:

$$
\frac{1}{U}=\frac{r_{o}}{r_{i}} \times \frac{1}{h_{i}}+\frac{1}{h_{o}}
$$

where $h_{i}$ is inside heat transfer coefficient, $h_{o}$ outside heat transfer coefficient, $r_{i}$ and $r_{o}$ are inside and outside radii of the tube. For a parallel flow heat exchanger, the length, $L_{\mathrm{he}}$ and area, $A_{\text {he }}$ can be estimated using the expressions by [22]:

$$
A_{\mathrm{he}}=\pi d_{0} L_{\mathrm{he}}
$$

and

$$
L_{\mathrm{he}}=\frac{\dot{Q}}{U \times\left(\pi d_{o} \theta_{m}\right)}
$$

\subsection{Thermal Insulation of the Drying Chamber}

The drying chamber is thermally insulated to avoid excessive heat losses through its walls. The thickness of the heat insulating (lagging) material was determined using an analogy of heat transfer through a composite wall. The chamber wall is made of mild steel plates at the internal and external parts while the heat lagging material (fiber glass) is placed in-between the mild steel plates of the chamber walls as shown in Figure 6.

The thermal conductivities of the three layers of the wall are as follows: $k_{1}, k_{2}$, and $k_{3}$, while their thicknesses are as follows: $x_{1}, x_{2}$, and $x_{3}$, respectively. The temperatures of the inner and outer surfaces of the drying chamber walls are $t_{1}$ and $t_{4}$ while the interface temperatures are $t_{2}$ and $t_{3}$, respectively. However, for continuity of flow to be achieved, the rate of heat transfer $\dot{q}$ through the layers of the wall must be the same. In addition, the

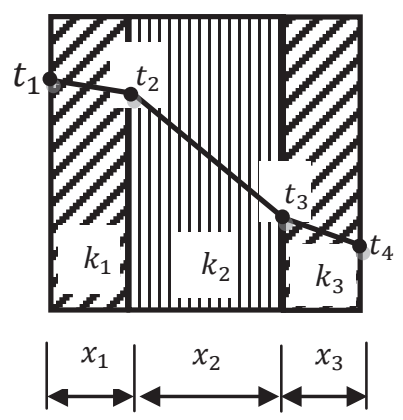

FIGURE 6. Lagging of the drying chamber walls. 
internal and external parts of the chamber are of the same material and thickness. Hence, $k_{1}=k_{3}$ and $x_{1}=x_{3}$. Thus, by Fourier's equation of heat transfer, we have:

$$
\dot{q}=\frac{k_{1} A\left(t_{1}-t_{2}\right)}{x_{1}}=\frac{k_{2} A\left(t_{2}-t_{3}\right)}{x_{2}}=\frac{k_{1} A\left(t_{3}-t_{4}\right)}{x_{1}}
$$

\subsection{The Fan/Blower Selection}

Blowers are sized based on the volume of air delivery and static pressure. In this work, the blower is powered by the electricity generated by the dynamo which is driven by the waste energy recovery turbine. The work done by the heat source per unit time, $P_{\mathrm{ht}}$ is equivalent to the work done on the ambient air, $P_{a}$ [21]. Thus:

$$
P_{\mathrm{ht}}=P_{a}=\dot{m}_{a} c \Delta T
$$

where $\dot{m}_{a}$ is mass flow rate of air, $c$ is specific heat capacity of air, and $\Delta T$ is the difference in the values of the maximum allowable temperature of the product to be dried and the ambient temperature. From Ref. [21], discharge of the heated air, $D$ is given by:

$$
D=\dot{m}_{a} v_{a}
$$

where $v_{a}$ is the specific volume of air. The velocity of air, $c_{a}$ required through the drying chamber [21], is calculated thus:

$$
c_{a}=\frac{D}{A_{2}}
$$

where $A_{2}$ is the area of the drying chamber's floor. From Ref. [21], the static pressure loss due to sudden enlargement is given by:

$$
L_{\text {se }}=\frac{U_{1}^{2}}{2 g\left(1-\frac{A_{1}}{A_{2}}\right)}
$$

where $U_{1}$ is the linear velocity of air in the heat exchanger; $g$ is the acceleration due to gravity; and $A_{1}$ is the area of the heat exchanger. The horsepower of the blower, $B_{\mathrm{hp}}[21]$ is obtained using the expression below:

$$
B_{\mathrm{hp}}=\frac{D \times p_{\mathrm{st}}}{6320 \times \xi_{\mathrm{b}}}
$$

where $\left(6320 \times \xi_{\mathrm{b}}\right)$ is called the conversion factor and $\xi_{\mathrm{b}}$ is the blower efficiency, $D$ is the airflow rate (in CFM), and $p_{\text {st }}$ is the static pressure in inches of water. 


\section{Discussion}

Heat recovery from the high heat content exhaust gases exiting the tail pipe of diesel powered electric generators has barely received any meaningful attention by researchers. Yet, this enormous heat is directly dumped into the environment even though it could still be harnessed and transferred to a productive end-use. The reason behind the unavailability of research works done in this area could perhaps be due to the inability of researchers to identify any meaningful and beneficial application of the energy recoverable from these systems using available techniques. However, it is pertinent to note that heat recovery from stationary diesel generators can be used effectively to power dryers for the preservation of agricultural products. This is achievable by an appropriate arrangement of the components of the energy recovery turbine, the heat exchanger and the tray dryer as demonstrated in this work. In a conventional tray dryer, the blower required for its operation is usually attached to the dryer where it blows air across the heating source and supplies the resulting hot air to the trays holding the materials to be dried. However, the blower used in this work has no direct connection with the dryer. It is rather connected to the heat exchanger into which it drives air to be heated by the exhaust gas passing through the heat exchanger, and the heated air is then routed to the drying chamber of the dryer through a duct for drying of products. In addition, unlike in most heat recovery systems, it is interesting that in this work, there are two stages of energy recovery. The first stage is the energy recovery turbine while the second stage involves the use of a heat exchanger to further recover heat from the exhaust gas exiting the turbine housing. The test rig of this whole equipment has been fabricated and is currently undergoing experimental investigation.

Preliminary test of the dryer showed high drying rate of maize grains. During the test, the tray dryer was initially allowed to run without load for a period of $45 \mathrm{~min}$; and the air temperature and humidity of $88^{\circ} \mathrm{C}$ and $22.3 \%$ were recorded in the drying chamber for an air speed of $2.0 \mathrm{~m} / \mathrm{s}$. The initial temperature and humidity of the chamber were $31^{\circ} \mathrm{C}$ and $71.2 \%$, respectively. Subsequently, the three trays of the dryer were loaded with grains of freshly harvested maize after the chamber had been cooled and averagely maintained at $59^{\circ} \mathrm{C}$. The trays contained $400 \mathrm{~g}$ each of the grains and the dryer was allowed to run for a period of $30 \mathrm{~min}$. The results obtained showed weight losses of $127.81 \mathrm{~g}, 118.36 \mathrm{~g}$, and $116.91 \mathrm{~g}$ for the grains in trays 1, 2, and 3, respectively. Detailed results of experiments on the drying of freshly harvested maize grains and other crops such as yam and cassava chunks, etc. will be made available (with results analyses) in due course. Performance evaluation of the tray dryer will be carried out; and the specific energy consumption, effective moisture diffusivity, and activation energy for the thin-layer drying of the crops will be determined. The proximate analyses of the dried products will also be obtained in order to determine their chemical and nutritional values.

\section{Conclusion}

The sizing of the equipment and method of utilizing exhaust gas waste heat for food crops drying have been considered. The sizing of the components of the equipment was achieved 
using known design principles. The concept is geared towards recovery and utilization of waste heat of a diesel engine thereby helping to reduce the quantity of pollutants released into the environment. The recovered energy may be put to useful work, such as drying of products, instead of resorting to burning of fresh fuels to do the same work. It is intended that the application of the recovered waste energy (from the exhaust gas of Internal Combustion engines) to drying, would reduce the energy demand for the depleting fossil fuel reserves which saves a considerable amount of primary fuel; help farmers to minimize the amount of agricultural product losses usually incurred during postharvest, thus improving the value and profit margin of the farmers, and hence the impact of global warming.

\section{References}

1. Ali Mohammad RV. Waste heat recovery power generation systems for cement production process. IEEE Transactions on Industry Applications. 2015; 51(1), 511-516.

2. Jadhao JS, Thombare DG. Review on exhaust gas heat recovery for I.C. engine. International Journal of Engineering and Innovative Technology. 2013; 12, 93-100.

3. Saidur R. Technologies to recover exhaust heat from internal combustion engines. Renewable and Sustainable Energy Reviews. 2012; 16, 5649-5659.

4. Nadaf SL, Gangavati PB. A review on waste heat recovery and utilization from diesel engines. International Journal of Advanced Engineering Technology. 2014; 4, 31-39.

5. Pradip GK, Hole JA. A review on waste heat recovery and utilization from exhaust gas of I.C engine. International Journal for Scientific Research \& Development. 2015; 3, 1321-1325.

6. Hatazawa M, Sugita H, Ogawa T, Seo Y. Performance of a thermo acoustic sound wave generator driven with waste heat of automobile gasoline engine. Transactions of the Japan Society of Mechanical Engineers. 2004; 70, 292-299.

7. Stabler F. Automotive Applications of high efficiency thermoelectric. Proceedings of the DARPA/ONR program review and DOE high efficiency thermoelectric workshop, San Diego. 2002, 1-26.

8. Bergmeier M The history of waste energy recovery in Germany since 1920. Energy. 2003; 13, 1359-1374.

9. Makanjuola GA, Abimbola TO, Anazodo UG. Agricultural mechanization policies and strategies in Nigeria. Proceedings of a workshop on agriculture, mechanical and strategies in Africa. 1991; 99-120.

10. Aasa SA, Ajayi OO, Omotosho OA. Design optimization of hot air dryer for yam flour chunk. Asian Journal of Scientific Research. 2012; 3, 143-152.

11. Odigboh EU. Continuing controversies on tillage mechanization in Nigeria. Journal of Agricultural Science and Technology. 1991; 1, 41-49.

12. Tiwari GN. Solar Energy Fundamentals, Design, Modeling and Application. Narosa Publishing House PVT Ltd., New Delhi. 2012; 203-250.

13. Ehiem, JC, Irtwange SV, Obetta SE. Design and development of an industrial fruit and vegetable dryer. Research Journal of Applied Sciences, Engineering and Technology. 2009; 2, 44 -53.

14. Donald GM. A basic guide to drying fruits and vegetables. Department of Food Science University of Guelph Ontario, Canada. https://es.scribd.com (2012). Accessed 19 February 2018. 
15. Katiyar A, Sudhakar K. A review on the tray dryer system for agricultural products. Energy Centre, Maulana Azad National Institute of Technology, Bhopal (M.P), India. Accessed 13 December 2013.

16. Misha S, Mat S, Ruslan MH, Sopian K, Salleh E. Review on the application of a tray dryer system for agricultural products. World Applied Sciences Journal. 2013; 3, 424-433.

17. Boyce MP. Axial-flow turbines. Gas Turbine Engineering Handbook. Gulf Professional Publishing, Houston, TX, USA. 2011; 9: 337-369.

18. Eastop TD, MacConkey A. Applied Thermodynamics for Engineering Technologists. (5thedn), Pearson Education Ltd, Panchsheel Park, New Delhi, India. 2005. ISBN: 978-81-7758-238-3.

19. Sioutas C, Delfino RJ, Singh M. Exposure assessment for atmospheric ultrafine particles (UFPs) and implications in epidemiologic research. International Journal of Environmental Health Research. 2005; 113, 947-955.

20. Ajala AS, Ngoddy PO, Olajide JO. Design and Construction of a Tunnel Dryer for Food Crops. International Multidisciplinary Research Journal. 2018. doi:10.25081/imrj.2018.v8.3449

21. Adzimah K, Seckley E. Improvement on the design of a cabinet grain dryer. American Journal of Engineering and Applied Sciences. 2009; 2, 217-228.

22. Rajput RK. Heat and Mass Transfer in S. I. Units. (3rd edn). S. Chand and Company Ltd. Ram Nagar, New Delhi. 2010. 